Journal of Advanced Research in Fluid Mechanics and Thermal Sciences

Journal homepage: www.akademiabaru.com/arfmts.html ISSN: 2289-7879

\title{
A CFD Study on the Significance of the Cavitation Modeling in Textured Bearing Analysis
}

\author{
Susilowati ${ }^{1,}{ }^{*}$, Muchammad $^{2}$, Mohammad Tauviqirrahman $^{3}$, Jamari $^{3}$ \\ 1 Chemical Engineering Departement, Faculty of Engineering, Universitas Pembangunan Nasional “Veteran” Jawa Timur, Jl. Raya Rungkut Madya, \\ Gunung Anyar, Surabaya, Indonesia \\ 2 Laboratory for Surface Technology and Tribology, Faculty of Engineering Technology, University of Twente, Drienerlolaan 5, Postbus 217, 7500 \\ $A E$, Enschede, The Netherlands \\ 3 Mechanical Engineering Department, Engineering Faculty, Diponegoro University, Jl. Prof. H. Soedharto, Tembalang, Semarang, 50275, \\ Indonesia
}

ARTICLE INFO

\section{ABSTRACT}

\section{Article history}

Received 29 January 2020

Received in revised form 3 April 2020

Accepted 12 April 2020

Available online 27 May 2020

Keywords:

Inertia; cavitation; CFD (computational fluid dynamics); lubrication

\begin{abstract}
In this paper, the effect of cavitation modeling on the lubrication performance (i.e., load support, friction) is investigated by computational fluid dynamics (CFD) approach. The comparison of the lubrication performance between the analysis with the cavitation model and that without cavitation model is of particular interest. Results are presented for two patterns of textured bearing, i.e., bearing with high inertia and one with low inertia. Based on the simulation results, the inclusion of cavitation modeling has a strong effect of the load support as well as the friction force. The "no-cavitation" cases lead to under-estimation of the predicted performance of lubrication. It is also shown the presence of the inertia is proven to increase the load support.
\end{abstract}

Copyright @ 2020 PENERBIT AKADEMIA BARU - All rights reserved

\section{Introduction}

In the last centuries, the research of surface texturing of the bearing has obtained an explosion interest by workers around the world. It is well accepted that the surface texturing approach has proven to enhance the lubrication characteristics. Numerous workers based on lubrication theory have introduced several mechanisms of lift generation of textured surfaces, including the cavitation. Fowell et al., [1], based on the mass-conserving numerical analysis, stated that any convergence between the bearing surfaces provides a significant mechanism for lift generation. The "inlet suction" was proven as a mechanism for creating additional load support. The cavitation phenomena in bearing were in more detail studied.

\footnotetext{
* Corresponding author.

E-mail address: zuzisukasno@gmail.com (Susilowati)
} 
Similarly, Gherca et al., [2] investigated the effects of texture geometry using a mass-conserving model. It was highlighted that the load support was strongly affected by the geometrical features such as size, density, and shape. Henry et al., [3] experimentally studied the effect of surface texturing on the steady-state behavior of bearings. It can be found that the textured bearings reduce friction up to $30 \%$ at low loads, while for heavy loads, their performance is equivalent or even lower than that of an untextured bearing. Yagi et al., [4] studied the value of the load support enabled by the textured pattern in the hydrodynamic lubrication regime. They concluded that the mechanism of lift generation was strongly affected by boundary conditions. Zhang et al., [5] investigated the effect a rectangular array of circle dimples on the film thickness profile. It was concluded that the lift generation could be improved through the appropriate partial arrangement of textures. Later, Shinde and Pawar [6] proposed the optimal surface texturing parameters to improve the performance of bearing. For improving the accuracy of the prediction, Muchammad et al., [7-8] considered the cavitation effect in solving the lubrication problem of the textured bearing.

Based on the literature survey, it can be highlighted that the cavitation strongly influences the lubrication performance. However, most of the published works, the cavitation is not modeled adequately because the single-phase analysis was assumed. In recent publications, some workers have used the multi-phase cavitation modeling to capture the cavitation phenomena, for example, [9-13]. It was found that such an approach matches well with the experiment results.

The present work based on the CFD method focuses on how important the cavitation model should be included when the lubrication problem is of particular interest. Additionally, in the present study, two different textured bearings are considered dealing with the inertia effect.

\section{Methodology}

In the present study, the lubrication problem is solved by the Navier-Stokes and continuity equations. The Navier-Stokes (N-S) equations are solved over the domain using a finite-volume method with the commercial CFD software package FLUENT ${ }^{\circledR}$. Not like the previously published works in which the cavitation model is ignored, in the present study, the cavitation effect is taken into account. In this study, the Zwart-Gelber-Belamri is employed due to its capability (less sensitive to mesh density, robust, and converge quickly [14]. For Zwart-Gelber-Belamri model, the final form of the cavitation is as follows

$$
\begin{aligned}
& \text { if } p \leq p_{v}, R_{g}=F_{\text {evap }} \frac{3 \alpha_{\mathrm{nuc}}\left(1-\alpha_{v}\right) \rho_{v}}{R_{B}} \sqrt{\frac{2}{3} \frac{P_{v}-P}{\rho_{\ell}}} \\
& \text { if } p \geq p_{v}, R_{C}=F_{\text {cond }} \frac{3 \alpha_{v} \rho_{v}}{R_{B}} \sqrt{\frac{2}{3} \frac{P-P_{v}}{\rho_{\ell}}}
\end{aligned}
$$

where $F_{\text {evap }}=$ evaporation coefficient $=50, F_{\text {cond }}=$ condensation coefficient $=0.01, R_{B}=$ bubble radius $=10^{-6} \mathrm{~m}, \alpha_{\text {nuc }}=$ nucleation site volume fraction $=5 \times 10-4, \rho_{\mathrm{I}}=$ liquid density and $\mathrm{p}_{\mathrm{v}}=$ vapor pressure .

Figure 1 shows the computational domain of textured slider bearing. The model used here is inspired by the work of Dobrica dan Fillon [15]. The CFD model has $\rho_{t}=0.5$ and $S=1.0$. The no-slip boundary condition is employed, and the isothermal condition is assumed. The bottom of the bearing is the moving wall. Two cases of the simulation are used here; that is, first, the case with 57.3 and $\lambda$ $=2$ and second, the case with $\operatorname{Re}=5$ and $\lambda=20$. For the top surface, the stationary surface is assumed. The commercial software based on the finite volume method ANSYS Workbench 16.0 is used to solve 
the lubrication problem. As a note, $\lambda$ is defined as the ratio between the dimple length and dimple depth.

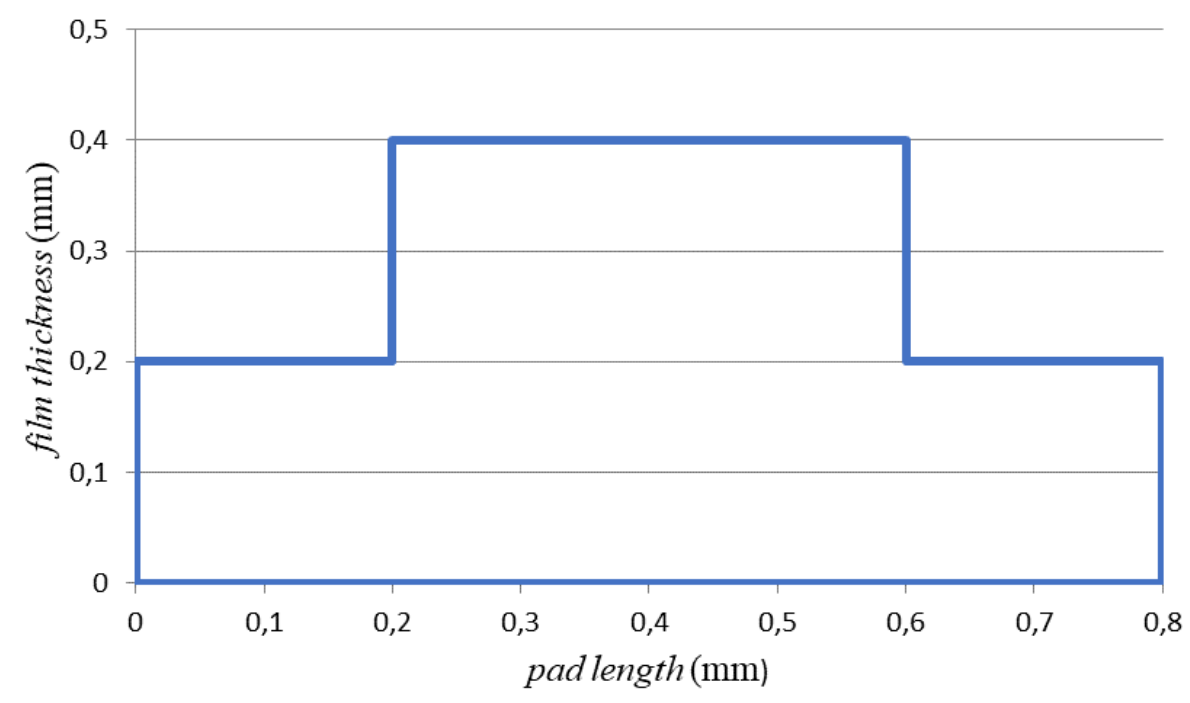

Fig. 1. Computational domain of textured slider bearing

Figure 2 shows the boundary condition employed in this study. At two sides of the domain, the periodic boundary condition is used. In the present study, to obtain more accurate results, the massconserving cavitation model, as mentioned earlier, is adopted. For calculation, the lubricant density $\rho$ is $860 \mathrm{~kg} / \mathrm{m}^{3}$, and the lubricant dynamic viscosity $\eta$ is 0.03 Pa-s. For the vapor behavior, the parameter is as follows: the vapor density $\rho_{\text {vap }}$ is $1.256 \times 10 \mathrm{~kg} / \mathrm{m}^{3}$, and the vapor viscosity $\eta_{\text {vap }}$ is 0.02556 Pa-s.

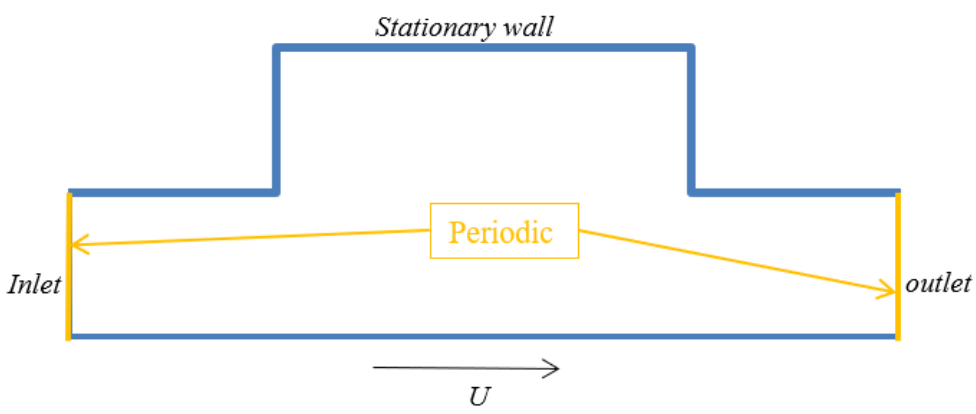

Fig. 2. Boundary condition used in this study

Figure 3 depicts the meshed model of textured slider bearing. In the present study, the model is discretized with the rectangular mesh with a high density of mesh to capture the physical phenomena during the lubrication process. Additionally, more refinement of the mesh is performed inside the texture. For more detail, the mesh specification used in this study is reflected in Table 1. 


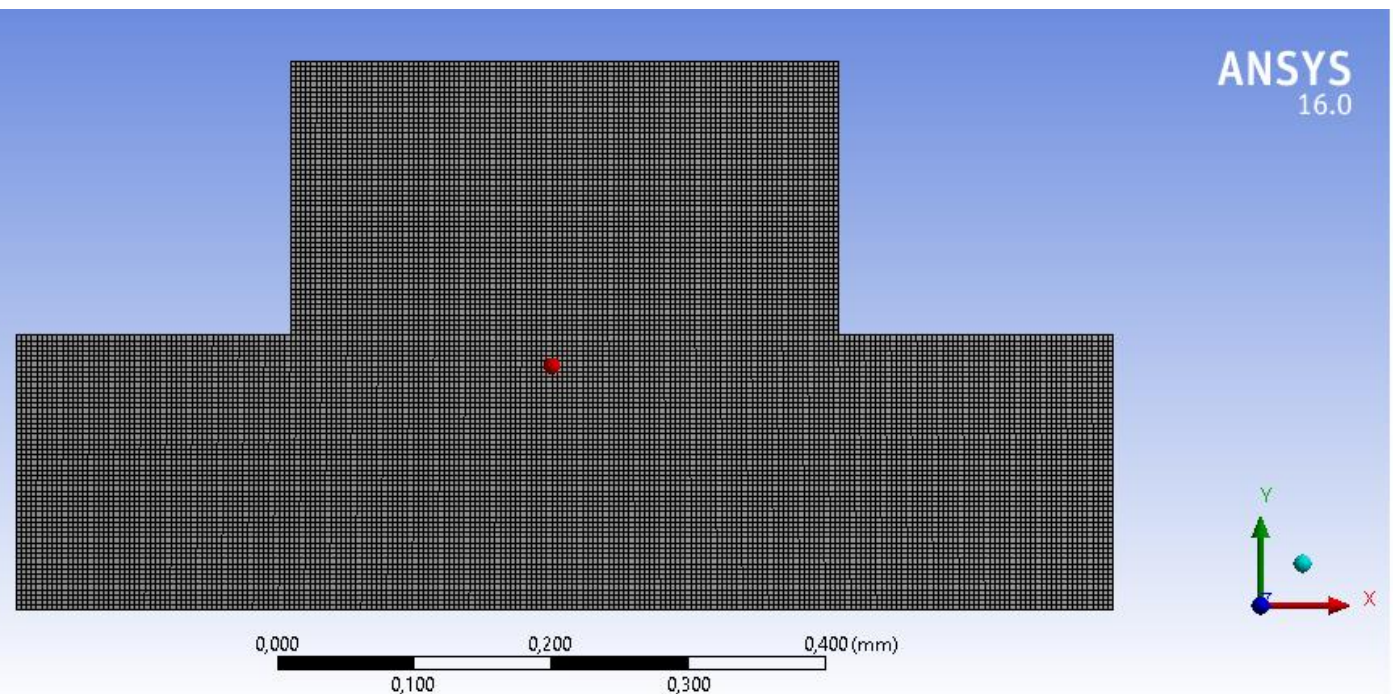

Fig. 3. Meshing the model

Table 1

Mesh specification of textured slider bearing model

Method

Quadrilateral

Sizing

$3.75 \times 10^{-3} \mathrm{~mm}$

Elements number

169,960

Nodal number

17,280

Max Skewness

$2.99 \times 10^{-3}$

Min Skewness

$4.33 \times 10^{-7}$

Average Skewness

$1.02 \times 10^{-3}$

\section{Results}

\subsection{Validation}

In this section, the validation of the developed CFD model is performed to ensure the correct solution set up. The work of Dobrica and Fillon [15] is chosen in the case of textured slider bearing in particular with a specific pattern, i.e., $\operatorname{Re}=57.3$ and $\lambda=2$. As a note, in [15], the Reynolds equation was used to solve the lubrication problem. Figure 4 shows the comparison of the pressure between the present study and the published work. It can be observed that the present results match the reference well. It indicates that the developed solution set up is acceptable, and thus it can be used to solve other cased with different patterns. 


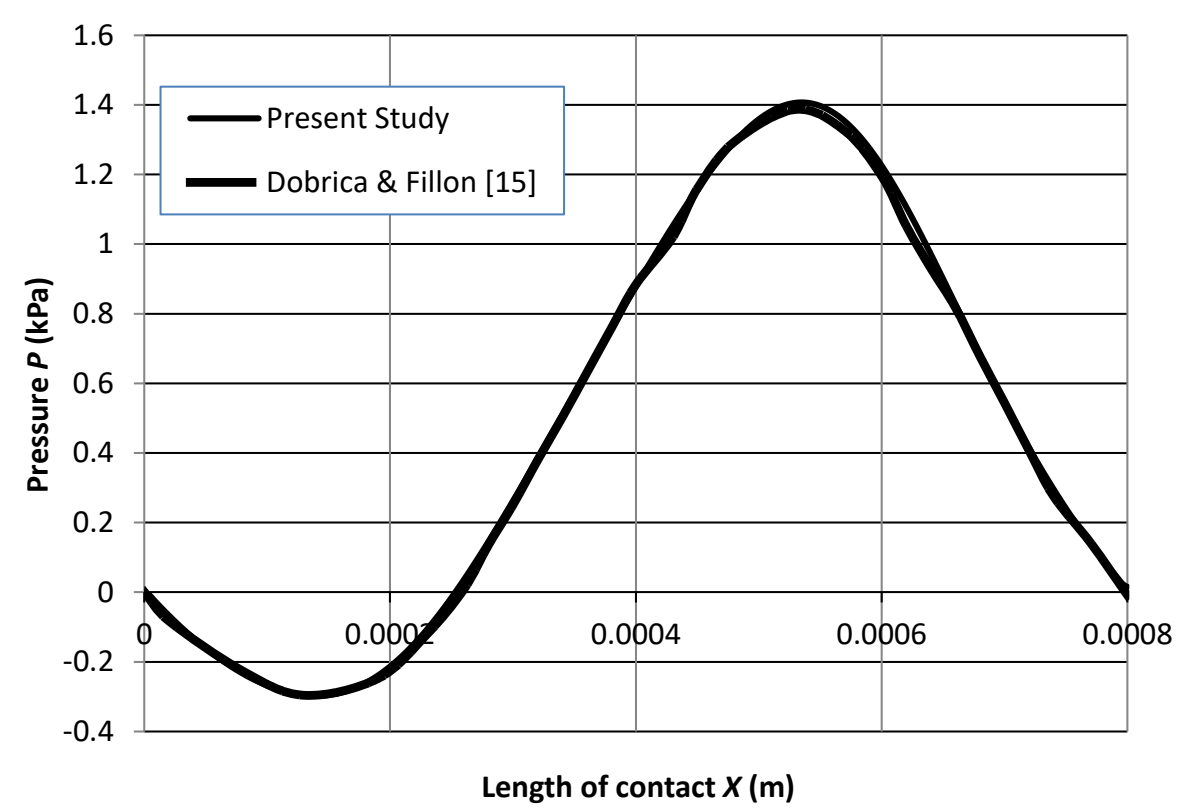

Fig. 4. The comparison of the pressure between the present study and the published work [16]. Results are evaluated at $\operatorname{Re}=57.3$ and $\lambda=2$

\subsubsection{Effect of Cavitation}

Figure 5 shows the comparison of the pressure between the analysis with the cavitation model and that without the cavitation model. It can be observed that the cavitation modeling gives a slightly different profile of pressure compared to the analysis without cavitation. It seems that there is a cavitation phenomenon that occurs at the textured bearing. A shift of the pattern is found when the comparison of the pressure is conducted.

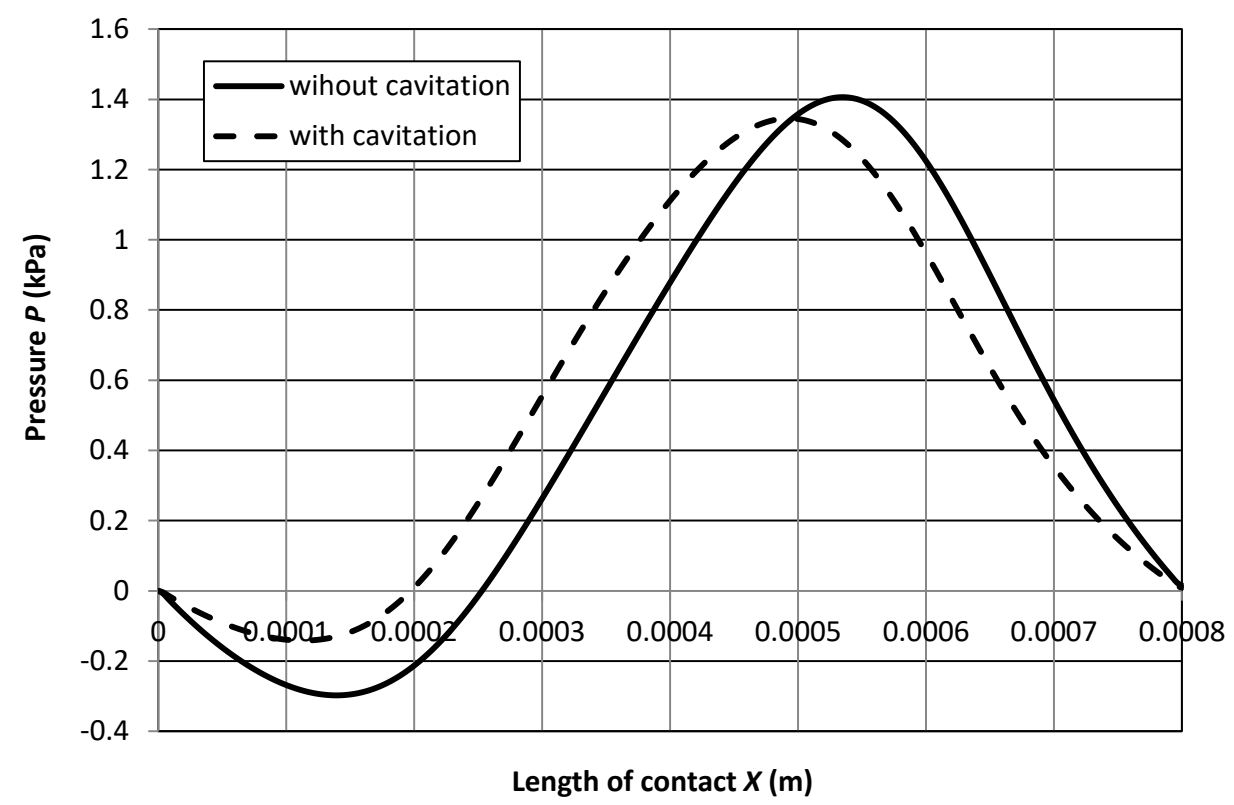

Fig. 5. The comparison of the pressure between the analysis considering the cavitation model and that without cavitation model. Results are evaluated at $\operatorname{Re}=57.3$ and $\lambda=2$ 
For the case of textured bearing with low inertia effect (i.e., $\operatorname{Re}=5.73$ and $\lambda=20$ ), the comparison of the pressure between the analysis considering the cavitation model and that without cavitation model is shown in Figure 6. It can be seen from Figure 6, that the textured bearing with less inertia effect gives a very similar profile of pressure compared to the case with higher inertia, as shown in Figure 5. It indicates that the cavitation phenomena do not occur at the bearing with low inertia. This finding matches well with the recent publication [12]. Also, as predicted in this study, the introduction of the texturing is able to increase the improved performance of bearing, as discussed by Empaling et al., [16].

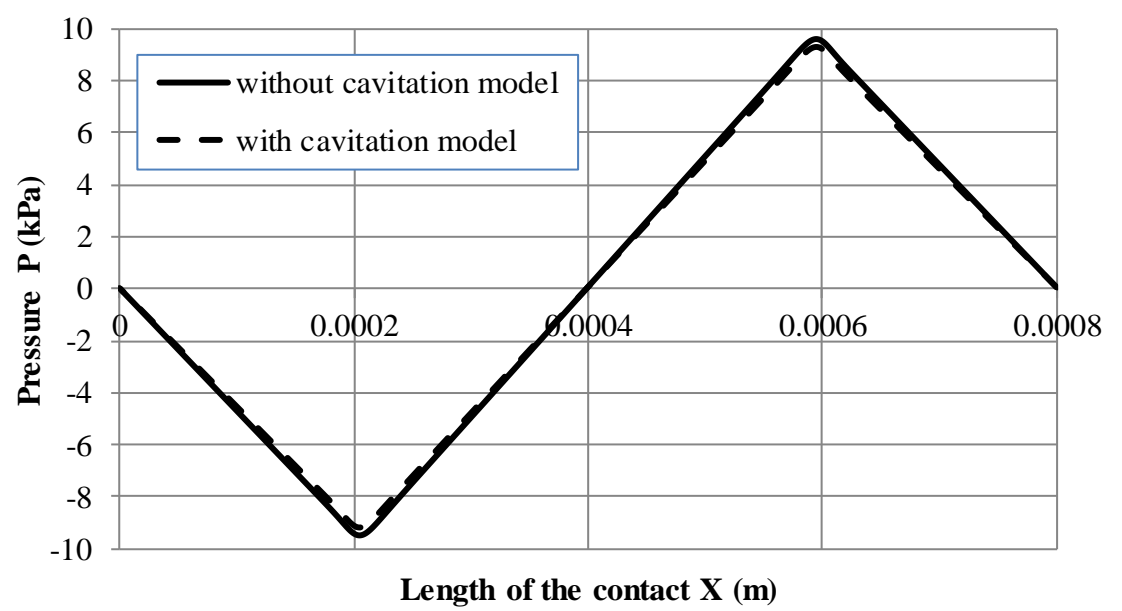

Fig. 6. The comparison of the pressure between the analysis considering the cavitation model and that without cavitation model. Results are evaluated at $\operatorname{Re}=5.73$ and $\lambda=20$

The load support as one of the indicators of tribological performance is obtained by integrating the pressure over the surface area. Figure 7 shows the load support for several configurations of textured bearings. It can be observed that the inertia effect has a strong role in creating additional load support. The increased load support becomes higher when the cavitation modeling is considered in the analysis.

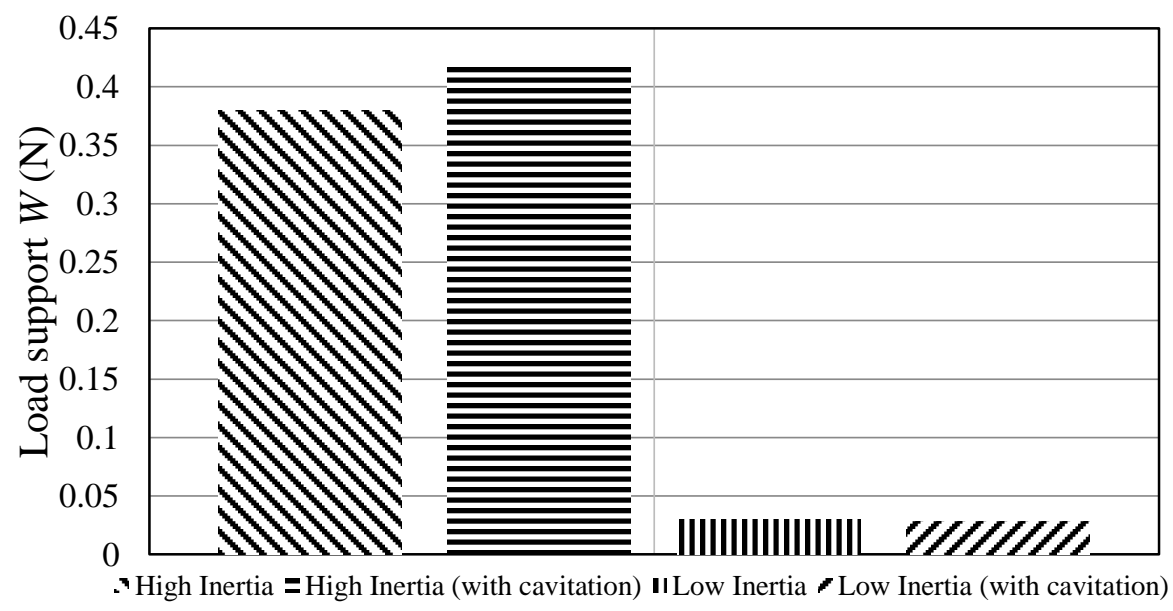

Fig. 7. Load support for several configurations 
Figure 8 shows the predicted friction force of textured patterns. The friction force is basically the integration of the shear stress over the surface contact. It can be seen that as expected, the solution with the cavitation model produced a higher friction force both for the case of low inertia and the high inertia. It strengthens the previous results in terms of the load support, which mentioned that the cavitation modeling is quite important to include in the analysis to get a more accurate result.

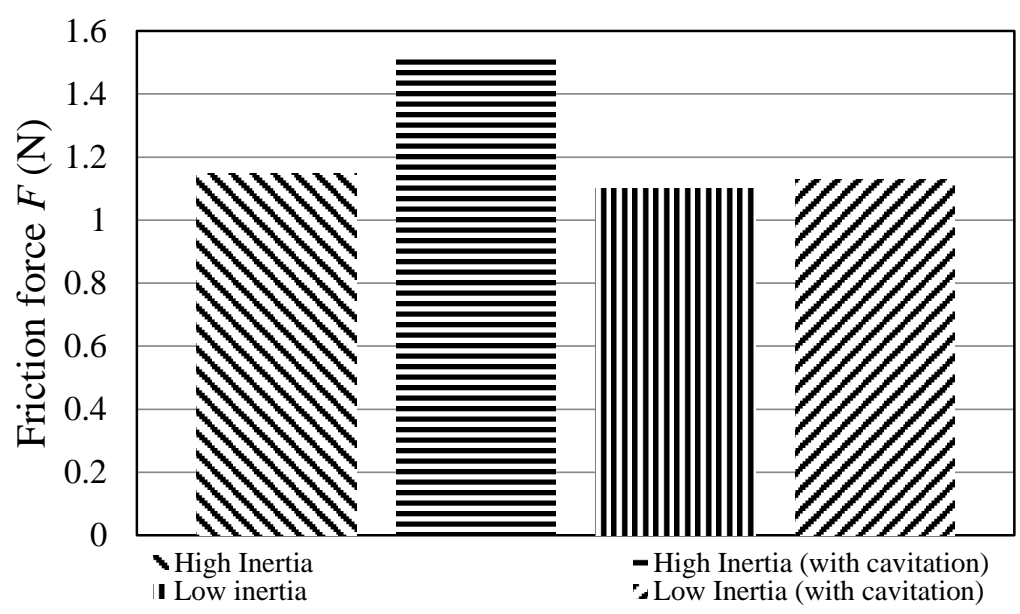

Fig. 8. Friction force for several configurations

\section{Conclusions}

In the present study, the computational fluid dynamics (CFD) method is used in solving the lubrication problem. The significance of cavitation modeling is evaluated. Additionally, the inertia effect which may present in the textured bearing is also of particular interest. Based on the discussion earlier, the conclusions can be drawn as follows

i. The inertia has a significant effect in enhancing the load support.

ii. The cavitation phenomena are proven to alter the flow characteristic. Thus, the cavitation modeling cannot be ignored when solving the lubrication problem in particular when the texturing of bearing exists.

\section{References}

[1] Fowell, M. T., S. Medina, A. V. Olver, H. A. Spikes, and I. G. Pegg. "Parametric study of texturing in convergent bearings." Tribology International 52 (2012): 7-16.

https://doi.org/10.1016/j.triboint.2012.02.013

[2] Gherca, A. R., P. Maspeyrot, M. Hajjam, and A. Fatu. "Influence of texture geometry on the hydrodynamic performances of parallel bearings." Tribology Transactions 56, no. 3 (2013): 321-332. https://doi.org/10.1080/10402004.2012.752550

[3] Henry, Y., J. Bouyer, and M. Fillon. "An experimental analysis of the hydrodynamic contribution of textured thrust bearings during steady-state operation: A comparison with the untextured parallel surface configuration." Proceedings of the Institution of Mechanical Engineers, Part J: Journal of Engineering Tribology 229, no. 4 (2015): 362-375. https://doi.org/10.1177/1350650114537484

[4] Yagi, Kazuyuki, Hajime Sato, and Joichi Sugimura. "On the magnitude of load-carrying capacity of textured surfaces in hydrodynamic lubrication." Tribology Online 10, no. 3 (2015): 232-245.

https://doi.org/10.2474/trol.10.232

[5] Zhang, Hui, Guangneng Dong, Meng Hua, Feifei Guo, and Kwai Sang Chin. "Parametric design of surface textures on journal bearing." Industrial lubrication and Tribology 67, No. 4 (2015): 359-369

https://doi.org/10.1108/ILT-08-2013-0089

[6] Shinde, Anil B., and Prashant M. Pawar. "Multi-objective optimization of surface textured journal bearing by Taguchi based Grey relational analysis." Tribology International 114 (2017): 349-357. 
https://doi.org/10.1016/j.triboint.2017.04.041

[7] Muchammad, Muchammad, Mohammad Tauviqirrahman, J. Jamari, and Dirk Jan Schipper. "An analytical approach on the tribological behaviour of pocketed slider bearings with boundary slip including cavitation." Lubrication science 29, no. 3 (2017): 133-152.

https://doi.org/10.1002/ls.1361

[8] Tauviqirrahman, Mohammad, and Dirk Jan Schipper. "Numerical investigation of texturing and wall slip in lubricated sliding contact considering cavitation." Tribology Online 12, no. 2 (2017): 67-75.

https://doi.org/10.2474/trol.12.67

[9] Tauviqirrahman, M., B. Muthik, M. Muchammad, A. W. Pratomo, and J. Jamari. "Effect of cavitation modelling on the prediction of the lubrication performance using CFD: A case study of journal bearing lubricated with nonnewtonian." International Journal of Engineering and Technology 8, no. 6 (2016): 2541-2546.

https://doi.org/10.21817/ijet/2016/v8i6/160806207

[10] Pratomo, A. W., M. Tauviqirrahman, M. Muchammad, A. P. Bayuseno, and J. Jamari. "Comparison between nonNewtonian and Newtonian lubrication of journal bearing considering cavitation using CFD." International Journal of Applied Engineering Research 12, no. 7 (2017): 1190-1193.

[11] Tauviqirrahman, Mohammad, J. Jamari, Bayu Siswo Wibowo, Hilmy Muhammad Fauzan, and M. Muchammad. "Multiphase Computational Fluid Dynamics Analysis of Hydrodynamic Journal Bearing Under the Combined Influence of Texture and Slip." Lubricants 7, no. 11 (2019): 97.

https://doi.org/10.3390/lubricants7110097

[12] Jamari, Jamari, M. Muchammad, F. Hilmy, and Muhammad Tauviqirrahman. "Effect of inertia on the cavitation phenomena of hydrodynamic textured bearings considering slip." Journal of the Brazilian Society of Mechanical Sciences and Engineering 41, no. 9 (2019): 387.

https://doi.org/10.1007/s40430-019-1890-9

[13] Tauviqirrahman, M., and A. Pratama. "Hydrodynamic Lubrication of Textured Journal Bearing Considering Slippage: Two-dimensional CFD Analysis Using Multiphase Cavitation Model." Tribology in Industry 41, no. 3 (2019). https://doi.org/10.24874/ti.2019.41.03.10

[14] ANSYS Help manual, release 16.0, Inc., Pittsburgh, Pennsylvania of USA ; 2017.

[15] Dobrica, M. B., and M. Fillon. "About the validity of Reynolds equation and inertia effects in textured sliders of infinite width." Proceedings of the Institution of Mechanical Engineers, Part J: Journal of Engineering Tribology 223, no. 1 (2009): 69-78. https://doi.org/10.1243/13506501JET433

[16] Shirly Empaling, Ahmad Zahran Md Khudzari, Muhammad Rashidi Abdul Kadir, Kahar Osman, Akmal Hakim Mohamad Hudzari, Mohammad Hasbullah Padzillah, Ishkrizat Abdul Talib, Mohamed Ezani Abdul Taib, and Aizai Azan Abdul Rahim."Spiral Groove Bearing Geometry Variation Effect on Left Ventricular Assist Device Impeller Performance." CFD Letters 11, no. 1 (2019): 86-101.

http://www.akademiabaru.com/doc/CFDLV11 N1 P86 101.pdf 